\title{
News Writing for Print ${ }^{1}$
}

\author{
Ricky Telg and Lisa Lundy²
}

\section{Introduction}

A good print news story will contain the following components: inverted pyramid structure, five Ws and $\mathrm{H}$, leads, objective writing, news writing techniques, quotations and attributions, Associated Press Style, and proper grammar and punctuation. Proper grammar and punctuation will be covered in a separate EDIS publication.

\section{Inverted Pyramid Structure}

The inverted pyramid structure is the most commonly used structure for news writing. The inverted pyramid presents the most important information in a news story first, followed in descending order by less-important information. This structure works well for two reasons. First, the most important information, which is presented at the beginning, helps to grab the reader's attention and interest, so the reader is more likely to read the entire article. Second, a story written in the inverted pyramid structure means the least important information is at the very end of the structure. Therefore, if the story needs to be cut, it can be cut from the bottom without any loss of important information. If you put important information at the end, it may get deleted. Additionally, with most consumers reading their news online, this helps ensure that they will see your most critical information even if they do not click through to read a full article.
The inverted pyramid structure is based on the "five Ws and $\mathrm{H}$ " and good leads. The lead, or first paragraph, is a simple statement that provides focus to the news story. A lead should be written as simply as possible and should contain as many of the five Ws and $\mathrm{H}$ as can be understood easily. The body of the inverted pyramid story adds detail to the information that has been introduced in the lead. The body should provide more information, supporting evidence, and context in the form of direct and indirect quotes, more details, and other descriptions.

Stories in the inverted pyramid structure avoid falling into the trap of a chronological storytelling of what happened at an event ("this happened, then this happened, then this happened"). For example, what happens at the beginning of a meeting or event is rarely the most important or interesting thing that occurred. Votes or policy recommendations often happen at the end of meetings.

\section{Inverted Pyramid Structure of News Writing}

The inverted pyramid is the structure most commonly used for news writing. The inverted pyramid presents the most important information in a news story first, followed in descending order by less-important information.

1. This document is AEC529, one of a series of the Department of Agricultural Education and Communication, UF/IFAS Extension. Original publication date January 2015. Revised June 2021. Visit the EDIS website at https://edis.ifas.ufl.edu for the currently supported version of this publication.

2. Ricky Telg, professor, and Lisa Lundy, professor, Department of Agricultural Education and Communication, UF/IFAS Extension, Gainesville, FL 32611.

The Institute of Food and Agricultural Sciences (IFAS) is an Equal Opportunity Institution authorized to provide research, educational information and other services only to individuals and institutions that function with non-discrimination with respect to race, creed, color, religion, age, disability, sex, sexual orientation, marital status, national origin, political opinions or affiliations. For more information on obtaining other UF/IFAS Extension publications, contact your county's UF/IFAS Extension office. U.S. Department of Agriculture, UF/IFAS Extension Service, University of Florida, IFAS, Florida A \& M University Cooperative Extension Program, and Boards of County Commissioners Cooperating. Nick T. Place, dean for UF/IFAS Extension. 


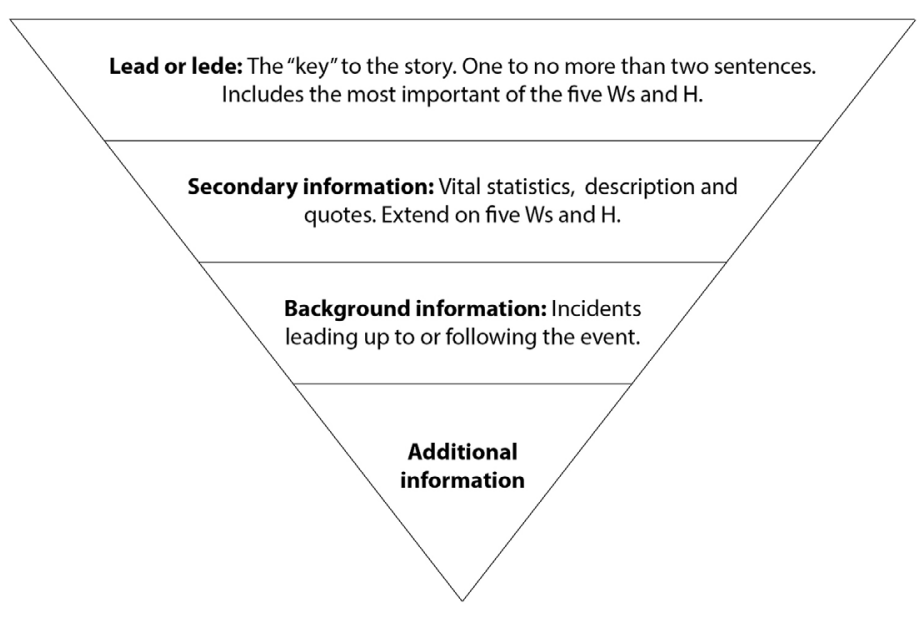

\section{Five Ws and $\mathrm{H}$}

The five Ws and $\mathbf{H}$ are the key components of any news stories. They stand for who, what, when, where, why, and how. The five Ws and $\mathrm{H}$ also can be the questions that a news story should answer, such as:

- Who said or did something?

- What was said or done? What happened?

- When was it said or done? When did it happen?

- Where was it said or done? Where did it happen?

- Why was it said or done? Why did it happen?

- How was it said or done? How did it happen? How does this affect me?

To gain the reader's attention you should begin the lead with the most interesting or most important element of the five Ws and $\mathrm{H}$. Others are added later in the story. The aspect used most often in the lead is the what, or perhaps the who, if it is someone important. What happened is usually what most people want to read about first.

\section{Leads}

The lead paragraph, lead or lede (pronounced LEED), is the first paragraph in the news story. The lead grabs the reader's attention and contains as many of the five Ws and $\mathrm{H}$ as can be understood easily. The reporter must make a judgment about what to put in a lead, based on the newsworthiness criteria described previously. A good lead generally will contain at least three of the five Ws and $\mathrm{H}$. However, one mistake writers sometimes make is trying to put too much in a lead. The lead should be brief, no more than 25 words. Following are descriptions of some types of leads that you might include in your stories.

The summary lead is the most common news-style lead seen in newspapers. The summary lead provides the most important of the five Ws and $\mathrm{H}$ elements. It gets the basic information up front. If you include a who in your lead, you do not have to use the person's name. You can identify someone by title or job position and then include the person's name later in the story. The following example shows how you can identify people without using their names. Unless the who in your story is someone important or well known, rarely will you want to list the person's name in the lead paragraph.

Example: Five Anyville 4-H members and a volunteer were injured Sunday night when their van slid out of control on icy roads in eastern Kentucky.

This summary lead contains who (five Anyville 4-H members and one volunteer), what (were injured when their van slid out of control), when (Sunday night), where (eastern Kentucky), and how (icy roads), and it is 25 words.

The question lead asks a question to grab the reader's attention. The question lead is seldom used because if a reader does not care about the answer to the question, then that person probably will stop reading.

Example: Will the older adult vote affect local elections?

Not if older adults are not registered to cast their ballots.

A quotation lead is a direct quotation used in the first paragraph. Unless the quotation is something memorable or unusual, the quotation lead should be avoided, because it is considered that the story's writer has given up on being creative and just inserted a quotation to jump-start a story. The following example shows how a quotation lead can work, because the quotation is out of the ordinary.

Example: "My plane is taking off without me," shouted a student pilot to his instructor as he dashed down the runway after the Cessna 140.

\section{Objective Reporter}

Another aspect of journalistic writing is the objective reporter. Now, because everyone can communicate with their target audiences, anyone can be a "reporter." To be a good reporter, though, you should follow these guidelines.

Reporters should be transparent in their writing. They should avoid using first-person pronouns (I, me, we, our, $m y, u s$ ) or second-person pronouns (you, your) outside of a source's direct quote.

Reporters also should set aside their own views and opinions. Allowing the writer's opinions, prejudices, and biases 
to enter a story is called editorializing. News reporters should report only what they see and hear. How a reporter feels about that information is not relevant to the news story. This is also important for communicators who write news stories or news releases about their organizations to share with news media. They should avoid being overly promotional in their writing.

To avoid editorializing, a writer should present only facts and limit or eliminate most adjectives, except in direct quotes. For example, instead of writing, "He was sad," describe what the person did that made you think he was sad. Instead of writing, "He was sad," you could write, "He placed his head in his hands and wept." Present what you see and hear; let the reader make the connection that the person was sad. How do you know something is "interesting," "impressive," "tragic," or "avoidable"? That is your opinion. Just present the facts. Leave the value judgment to your readers. Journalists often go by the adage, "Show, don't tell."

Editorializing can be avoided by attributing any information that is not a fact or is not common knowledge. If the information is not common knowledge, may or may not be true, or is entirely opinion, it must be attributed to someone. If not everyone knows something to be true, your responsibility is to attribute that information to a source.

You do not have to wrap up the story. That is one of the functions of the inverted pyramid structure. When there is nothing else to write, just stop.

\section{News Writing Techniques}

The following summarizes news writing techniques for print:

- Short sentences: Sentences in news stories average 20 to 25 words or so. Do not string together, with commas and conjunctions, several sentences into one long sentence. The best way to shorten sentences is to use periods, not commas and conjunctions.

- Short paragraphs: For news stories, paragraphs should be no more than three sentences long. Usually, paragraphs are one or two sentences long. This is much different than the writing you have done for your composition and English classes, which emphasizes four or five sentences per paragraph.

- Third person: A news story should be written completely in third person (e.g., he, she, it, they), except when you use a person's own words in a direct quotation.
- Nouns and verbs: Place emphasis more on nouns and verbs than on adjectives and adverbs. Overusing adjectives and adverbs will cause you to editorialize. Remove unnecessary adjectives like "very." Action verbs keep a story moving and grab the reader more than "to be" verbs (be, is, are, am, was, were), which show little action. Use action verbs to describe what you observe.

- Simple writing: Use simple words and simple sentences. Not every sentence should be in the simple-sentence format (subject-verb-object), but the simple sentence is a good tool for clearing up muddy writing.

- Jargon and clichés: Avoid jargon and clichés. Jargon is technical language used in specialized fields or in specific groups. Clichés are overused words and phrases, such as "it cost an arm and a leg," "a drop in the bucket," and "on the cutting edge."

- Transitions: Transitions tie together what you have written. Each sentence in a story should logically follow the previous sentence or should relate to it in some way. New information in a story should be connected to information already introduced. Transitions include the following:

- Connectors help unify the writing. For the most part, they are conjunctions such as and, but, or, for, thus, however, therefore, mean while, and others. They do not have great value in terms of the content of the writing, but they are necessary for its flow.

- Hooks are words or phrases that are repeated throughout an article to give the reader a sense of unity. For example, in a story about the city council, the word "council" used throughout the story would be a hook.

- Pronouns are one of the best transitional devices for writing about people. Instead of using a person's name each time, use a pronoun about every other time the person is mentioned in the story.

\section{Quotations and Attribution}

Quotations are the words of someone talking. It is a good idea to use quotations to bring "life" to your story. Quotations can be either direct or indirect. A direct quotationis the exact words of a person talking (or quoted) in a news story. An indirect quotation, also called a paraphrase, may have one word or a few of the same words that a speaker used, but it will also have words that the speaker did not use. Paraphrases express what the source said but with different words from those the speaker used. The exact words spoken by the speaker in a direct quotation or in an indirect quote will be inside quotation marks. Accuracy and context are critical for quotations. Make sure you have 
someone's words attributed accurately and do not take their words out of context.

A good news story will use more paraphrases than direct quotations. Direct quotations do add "life" to a story, but they should be used sparingly. Use them to supplement a story. Do not string together long sections of direct quotes.

Attribution means telling readers where the information in a story comes from. Attribution is extremely important in news writing. It is one way writers can avoid editorializing in their story, by making sure that information in their stories can be attributed to someone or some organization. Writers should attribute anything that is not common knowledge to all readers. Attributing information sources also allows the reader to assess the credibility of the information by assessing the source of the information. Some sources are more credible than others. Here are some examples of attribution:

Indirect quote/paraphrase: Myers said the incident was under investigation.

Indirect quote (with some of the words as the exact words of the speaker): Myers said the incident was being investigated, but that it would be "a long time before the investigation is completed."

Direct quote: "The incident is under investigation," Myers said.

Direct quote: "The incident is under investigation," Myers said, "but it will be a long time before the investigation is completed."

Following are some guidelines for attributing information and including quotations in news stories:

- Use the person's first name and last name when identifying a person by name for the first time in the story. This is also called "first reference." Afterward, use only the person's last name. Some newspapers use courtesy titles-such as Dr., Mr., Ms., and Mrs. - before the last name ("Ms. Becker," "Mr. Mallory"). However, the predominant practice is not to use courtesy titles. You do not have to include the person's last name each time you reference the person; you can use a pronoun (he, she) every other time, instead of the person's last name.

- Use quotation marks around a word or group of words when someone has spoken or written those exact words.

- Every quotation (direct or indirect) must have attribution.
- Each direct quotation should be its own paragraph. This may mean that the paragraph with a direct quotation is only one sentence.

- Use "said" for attribution. Many people try to look through a thesaurus for a different word to use, such as stated, noted, or exclaimed. Said is a neutral word. Use it.

\section{Associated Press Style}

The Associated Press is an international organization of professional journalists. The organization has a writing style for news stories. You must follow Associated Press Style if you are going to write news stories professionally or provide news releases about your events to news media. Every journalist and public relations professional must understand and use Associated Press (AP) Style.

It is recommended that you purchase an Associated Press Stylebook at least every two to three years to see if any additions to the Stylebook have been made or if any entries have changed. You can also pay for an online subscription through the website or app. For example, the 2006 Associated Press Stylebook listed "(123) 555-5678” as the correct way to include telephone numbers in a news story. The telephone number entry was changed in the 2007 Associated Press Stylebook to "123-555-5678." In the 2009 edition of the Stylebook, "website" was listed as two words: "Web site." In the 2010 edition, it had been changed to one word, not capitalized: "website." In addition, you should review the Stylebook's section on edit marks.

You may never need to know certain Associated Press Stylebook listings, such as if "nearsighted" is one word, two words, or hyphenated. (It is one word, by the way, according to the 2010 edition.) However, you will need to know how to correctly write an address and to use numbers and measurements, among other things. The following list of Associated Press tips is not meant to be a complete list of everything you should know, but it should keep you from having to memorize everything in the Stylebook.

\section{Numbers}

- In general, spell out whole numbers nine and below. (The nine boys)

- Use figures for 10 and above. (The 25 boys)

- "Million" and "billion" are used with round numbers. (2.3 million. 250 billion)

- “Thousands" are numbers. $(186,540)$

- Ages are always numbers. (The 2-year-old girl. John is 21 years old.) 
- Measurements and dimensions are always numbers. (25 percent. 3 yards. He is 5 feet tall.)

- Years are always numbers. (He was born in 1990.)

- However, spell out any number - except for a year - that begins a sentence. (Four-year-old Tom Adams won an award. 2007 was a good year.)

\section{Abbreviations}

- Titles: Some titles are abbreviated, but only in front of someone's name. The abbreviated titles are "Dr.", "Mr.," "Mrs.," "Rev." (reverend), "Sen." (senator), "Rep." (representative), "Gov." (governor), "Lt. Gov." (lieutenant governor), and military ranks. For example, "Gov. Adams said he liked the presentation." Titles are spelled out if they are not in front of a person's name. ("Adams, the governor of Georgia, said he liked the presentation.")

- Street addresses: The words "street," "avenue," and "boulevard" are spelled out unless they are part of a full street address. "Road," "alley," "circle," and "drive" are not abbreviated.

- He lives on Main Street. He lives at 1245 Main St.

- She lives on Bamboo Avenue. She lives at 405 Bamboo Ave.

- They live on Citrus Boulevard. They live at 80 Citrus Blvd.

- The box was delivered to Boone Road. The box was delivered to 890 Boone Road.

- Months and dates: Months are spelled out unless they come before a date. Check the Associated Press Stylebook to see how each month is abbreviated. Months that are five letters or shorter are never abbreviated (March, April, May, June, and July).

- She moved last February.

- She moved in February 2014.

- She moved on Feb. 6, 2014.

- She moved on March 15, 2014.

- Organizations: Spell out names of organizations (colleges, groups, clubs) on first reference. Abbreviate the names, if necessary, on second reference.

- First reference: College of Agriculture Student Council.

- Second reference: CASC

\section{Additional Information}

The Associated Press. (2022). The Associated Press stylebook and briefing on media law (55th ed.). New York: The Associated Press.

Burnett, C., \& Tucker, T. (2001).Writing for agriculture: $A$ new approach using tested ideas (2nd ed.). Dubuque, IA.: Kendall/Hunt.

Oliu, W. E., Brusaw, C. T., \& Alred, G. J. (2007). Writing that works: Communicating effectively on the job (9th ed.). Boston, MA: Bedford/St. Martin's.

Telg, R. \& Irani, T.A. (2012). Agricultural communications in action: A hands-on approach. Clifton Park, NY: Delmar. 